\title{
Virological and Epidemiological Situation in the Influenza Epidemic Seasons 2016/ 2017 and 2017/2018 in Poland
}

\author{
E. Hallmann-Szelińska, K. Łuniewska, K. Szymański, \\ D. Kowalczyk, R. Sałamatin, A. Masny, and L. B. Brydak
}

\begin{abstract}
The World Health Organization estimates that influenza virus infects 3-5 million people worldwide every year, of whom 290,000 to 650,000 die. In the 2016/2017 epidemic season in Poland, the incidence of influenza was 1,692 per 100,000 population. The influenza A virus, subtype $\mathrm{A} / \mathrm{H} 3 \mathrm{~N} 2 /$, was the predominant one in that season. However, in the most recent 2017/2018 epidemic season, the incidence exceeded 1,782 per 100,000 already by August of 2018. In this season, influenza B virus predominated, while the $\mathrm{A} / \mathrm{H} 1 \mathrm{~N} 1 /$ pdm09 strain was most frequent among the influenza A subtypes. The peak incidence, based on the number of clinical specimens tested, was in weeks 4-5 of 2017 and week 8 of 2018 in the 2016/2017 and 2017/2018 epidemic seasons, respectively. As of the 2017/2018 season, a quadrivalent vaccine, consisting of two antigens of influenza A subtypes and another two of influenza B
\end{abstract}

E. Hallmann-Szelińska ( $₫)$, K. Łuniewska,

K. Szymański, D. Kowalczyk, A. Masny,

and L. B. Brydak

Department of Influenza Research - National Influenza

Center, National Institute of Public Health - National

Institute of Hygiene, Warsaw, Poland

e-mail: ehallmann@pzh.gov.pl

R. Sałamatin

Department of General Biology and Parasitology, Warsaw Medical University, Warsaw, Poland virus, was available in Poland. Nonetheless, the vaccination rate remained at one of the lowest level in Europe, fluctuating between $3 \%$ and $4 \%$ of the general Polish population.

\section{Keywords}

Disease incidence $\cdot$ Epidemic season . Epidemiology $\cdot$ Infection · Influenza · Vaccination rate $\cdot$ Viral subtypes

\section{Introduction}

The influenza virus belongs to the Orthomyxoviridae family. It infects epithelial cells of the nose, larynx, trachea, and bronchi, damaging the epithelium of the respiratory system. The influenza A virus consists of eight RNA segments coding for at least ten proteins (Brydak 2008). It is divided into subtypes based on the properties of surface antigens, i.e., neuraminidase (NA) and hemagglutinin (HA). There are 18 antigenic HA subtypes (H1-H18) and 11 NA subtypes (N1N11) (Tong et al. 2013). Type B influenza virus is not categorized into subtypes. It is divided into two phylogenetically and antigenically different lines: Victoria and Yamagata, which are circulating worldwide in various proportions (Webster et al. 2013).

The epidemic season lasts from the beginning of October of a year to the end of September the 
following year (52 weeks). The annual influenza epidemic affects 3-5 million people worldwide, $20-30 \%$ of whom are children. Influenza is a health scourge causing severe complications. There are around 290,000-650,000 deaths yearly. Influenza B virus most often affects children and young adolescents ( $0-17$ years of age) and adults of 25-44 years of age (Vijaykrishna et al. 2015; Socan et al. 2014). Unlike the influenza A virus, the influenza $\mathrm{B}$ virus does not cause pandemics (Caini et al. 2015).

Poland has been a member of the European Influenza Surveillance Network (EISN) since 2001. Since the $2004 / 2005$ epidemic season, it has also participated in the Sentinel surveillance system. Virological and epidemiological data had initially been recorded in four age groups: $0-4$, $5-14,15-64$, and $\geq 65$ years of age. The system has been revised as of the 2013/2014 season to narrow the age group range to $0-4,5-9,10-14$, $15-25,26-44,45-64$, and $\geq 65$ years of age (Bednarska et al. 2016) in order to better illustrate the epidemiological situation.

The aim of this study was to investigate the virological and epidemiological situation during the two successive influenza epidemic seasons in Poland of 2016/2017 and 2017/2018.

\section{$2 \quad$ Methods}

The evaluation of the epidemiological situation in the epidemic seasons 2016/2017 and 2017/2018 was based on the data obtained from weekly epidemiological reports prepared jointly by the Department of Influenza Virus Research, National Center for Influenza of the National Institute of Public Health-National Institute of Hygiene (NIPH-NIH), and the Chief Sanitary Inspectorate in Warsaw, Poland. Reports concerned the incidence of both clinically and laboratory-confirmed influenza and influenzalike illnesses and also acute respiratory tract infections, according to the criteria set for the surveillance of influenza in the EU. Virological diagnostic tests were performed in the laboratories of the Provincial Sanitary and Epidemiological Stations and were verified in the
NIPH-NIH within the influenza surveillance Sentinel and non-Sentinel systems. The tests were performed on clinical samples collected by primary care physicians from patients suspected of being infected with influenza and influenza-like viruses. Molecular methods were employed to define the genetic viral material.

The genetic material was isolated from $200 \mu \mathrm{L}$ pharyngeal swab specimens suspended in physiological saline or phosphate-buffered saline (PBS). RNA isolations were performed using a Maxwell 16 Viral Total Nucleic Acid Purification Kit (Promega Corporation, Madison, WI). The procedure was carried out in accordance with the manufacturer's instructions. Molecular analysis was performed in a LightCycler 2.0 instrument (Roche Diagnostics, Rotkreuz, Switzerland). The reaction mixture contained the following ingredients in $20 \mu \mathrm{L}$ capillaries: $\mathrm{MgSO}_{4}$, bovine serum albumin (BSA), reaction buffer, RNAsefree water, SuperScript ${ }^{\circledR I I I / P l a t i n u m}{ }^{\circledR} T a q$ Mix (Invitrogen Life Technologies - Thermo Fisher Scientific, Carlsbad, CA), $0.5 \mu \mathrm{L}$ probe, and $0.5 \mu \mathrm{L}(20 \mathrm{nM})$ primers. Probes and primers were obtained from the International Reagent Resource (IRR) established by the Centers for Disease Control and Prevention (CDC). Five microliters of RNA was added to each sample of reaction mixture. Negative control was RNAsefree water, while positive control was RNA of strains included in the influenza vaccine for a given epidemic season.

To determine the influenza-like virus infection, clinical material was investigated using an RV15 OneStep ACE Detection Kit (Seegene, Seoul, South Korea). This multiplex kit detects genetic material of the following respiratory viruses: influenza types $\mathrm{A}$ and $\mathrm{B}$; adenovirus (ADV); respiratory syncytial viruses (RSV) A and $\mathrm{B}$; human metapneumovirus (hMPV); human coronavirus (hCoV); human parainfluenza viruse (hPIV) types: 1, 2, 3, and 4; human bocavirus (hBoV); and enterovirus (EV).

Data were expressed as counts of the incidence per 100,000 population in a given epidemic season, as total, and by age groups. Differences between the percentages of confirmed cases of influenza infection between the corresponding 
age groups of the two epidemic seasons were assessed with a two-sample $t$-test. A p-value of $<0.05$ defined statistically significant differences.

\section{$3 \quad$ Results and Discussion}

In the 2016/2017 epidemic season, i.e., from $01 / 10 / 2016$ to $30 / 09 / 2017$, a total of 3,977 specimens were tested in Poland, with a positive diagnostic yield of $44.9 \%$. Among positive samples, influenza viruses accounted for $94.5 \%$, whereas influenza-like viruses accounted for $5.5 \%$ of the infections. Virological molecular analysis revealed that $97.6 \%$ of influenza infections in the whole population were caused by type A virus, of which $66.8 \%$ were unsubtyped $\mathrm{A}$ virus and $31.2 \%$ were subtype $\mathrm{A} / \mathrm{H} 3 \mathrm{~N} 2 /$. The remaining $2 \%$ were infections caused by influenza type B virus. RSV predominated among influenza-like viruses $(85.7 \%)$. Figure 1 presents the percentage distribution of influenza viruses by age groups in the 2017/2018 season. The highest percentage of confirmed cases of influenza A infections was in the age group of 26-44 years (99.1\%), while that for influenza type B was in the age group of 5-9 years $(6.8 \%)$.
For comparison, in the 2017/2018 epidemic season, 5,793 specimens were tested, with a positive diagnostic yield of $43.8 \%$. In contrast to the preceding season when type A virus predominated, in this season type B virus was a dominant contagion. It accounted for $33.5 \%$ of confirmed influenza infections, whereas type B virus accounted for $63.3 \%$ and influenza-like viruses for $3.2 \%$ infections in the whole population. Among the subtypes of influenza A virus, subtype $\mathrm{A} / \mathrm{H} 1 \mathrm{~N} 1 / \mathrm{pdm} 09$ predominated in $85.9 \%$ of cases. RSV predominated in $63.1 \%$ of influenza-like infections. Figure 2 presents the percentage distribution of influenza viruses by age groups in the 2017/2018 season. The highest percentage of confirmed cases of influenza A infections was in the age group of $0-4$ years $(66.8 \%)$, while that for influenza type B was in the age group of $65+$ years $(76.6 \%)$.

The number of confirmed cases of influenza infections, relative to the number of samples tested, was significantly larger in the 2017/2018 season, compared with the preceding season, in the $0-4$ years $(\mathrm{p}<0.001), 5-9$ years $(\mathrm{p}=0.003)$, and $65+$ years $(\mathrm{p}=0.001)$ of age groups.

In the 2016/2017 season, overall 12 coinfection were detected: 9 between influenza viruses,

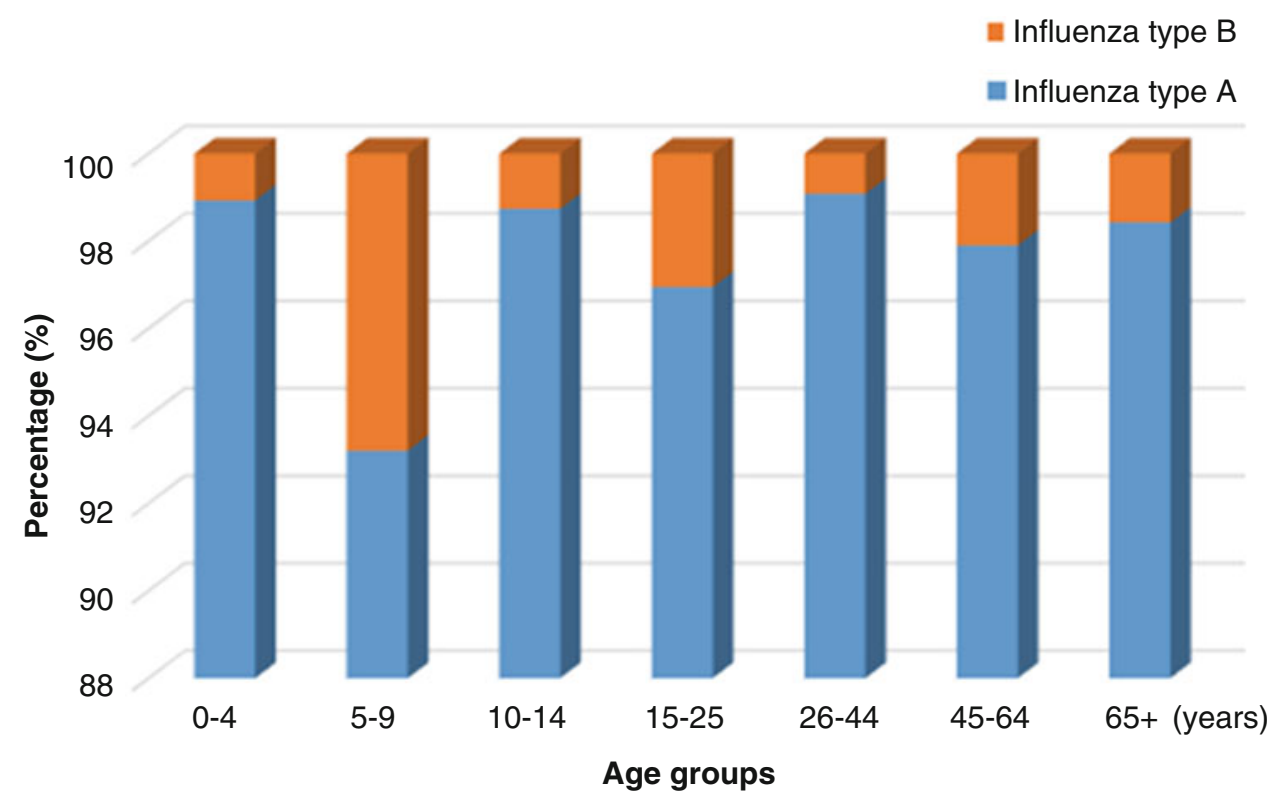

Fig. 1 Confirmations of influenza infection by age groups in the 2016/2017 epidemic season 


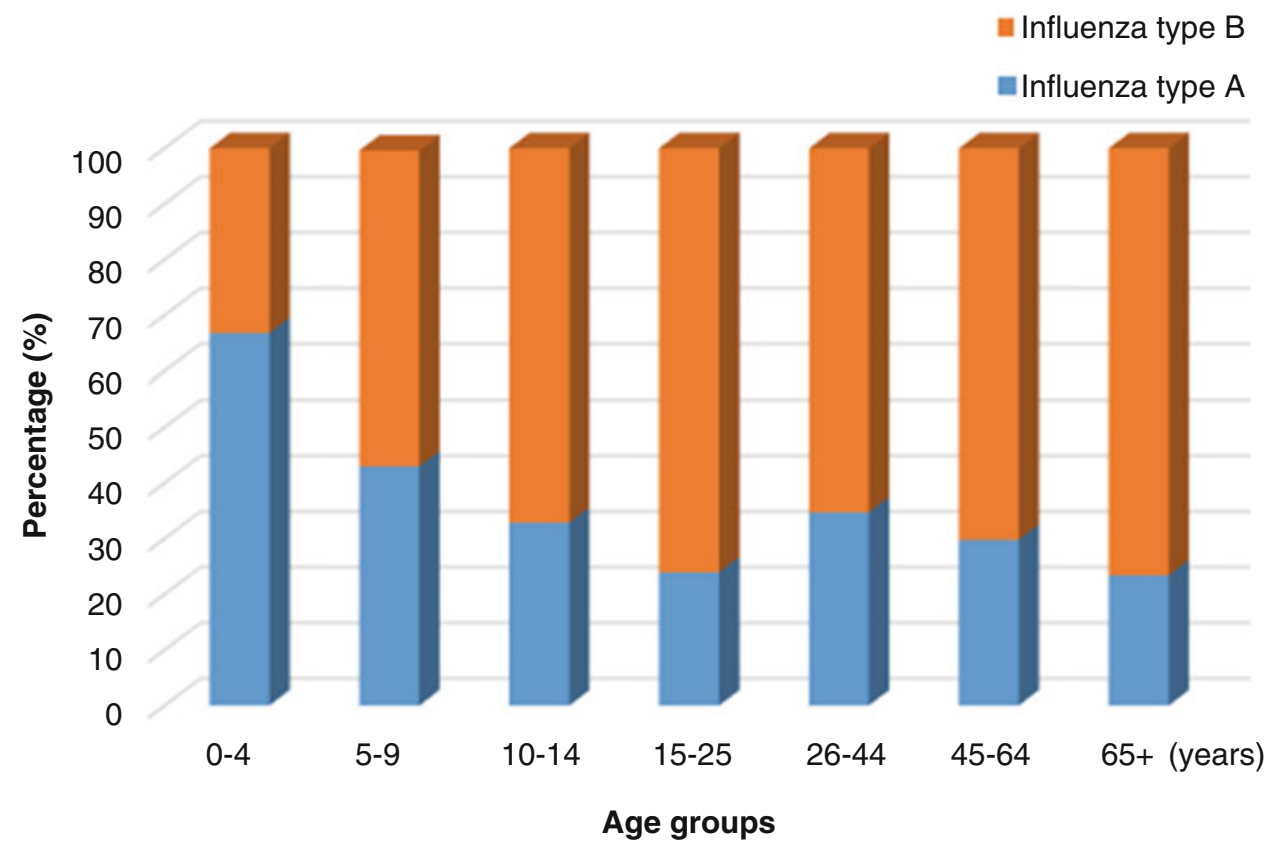

Fig. 2 Confirmations of influenza infection by age groups in the 2017/2018 epidemic season

Table 1 Coinfections in the 2016/2017 epidemic season

\begin{tabular}{l|l|l}
\hline Patient age (years) & Type of coinfection & Epidemic week \\
\hline 56 & $\mathrm{~A} / \mathrm{H} 3 \mathrm{~N} 2 /+\mathrm{B}$ & 50 \\
\hline 70 & $\mathrm{~A} / \mathrm{H} 3 \mathrm{~N} 2 /+\mathrm{B}$ & 50 \\
\hline 4 & $\mathrm{~A} / \mathrm{H} 3 \mathrm{~N} 2 /+\mathrm{B}$ & 51 \\
\hline 70 & $\mathrm{~A} / \mathrm{H} 3 \mathrm{~N} 2 /+\mathrm{B}$ & 51 \\
\hline 50 & $\mathrm{~A} / \mathrm{H} 3 \mathrm{~N} 2 /+\mathrm{B}$ & 51 \\
\hline 67 & $\mathrm{~A} / \mathrm{H} 3 \mathrm{~N} 2 /+\mathrm{B}$ & 51 \\
\hline 8 & $\mathrm{~A} / \mathrm{H} 3 \mathrm{~N} 2 /+\mathrm{B}$ & 1 \\
\hline 79 & $\mathrm{~A} / \mathrm{H} 3 \mathrm{~N} 2 /+\mathrm{B}$ & 2 \\
\hline 4 & $\mathrm{~A}+\mathrm{B}$ & 3 \\
\hline 70 & $\mathrm{~A} / \mathrm{H} 3 \mathrm{~N} 2 /+\mathrm{RSV}$ & 4 \\
\hline 63 & $\mathrm{PIV}-1+\mathrm{EV}$ & 5 \\
\hline 4 & $\mathrm{~A} / \mathrm{H} 3 \mathrm{~N} 2 /+\mathrm{RSV}$ & 7
\end{tabular}

$\mathrm{A}+\mathrm{B}$, influenza virus $\mathrm{A}$ and $\mathrm{B}$; RSV, respiratory syncytial virus; PIV-1, human parainfluenza virus type 1 ; EV, enteroviruses

2 between influenza A virus and RSV, and 1 between influenza-like viruses. However, there were no coinfections detected in the patients of 26-44 years of age (Table 1). On the other side, three coinfections in this age group were detected in the 2017/2018 season. Overall, there were 17 coinfections detected in the later season: 11 between influenza viruses, 2 between influenza viruses and influenza-like viruses, and 4 between influenza-like viruses (Table 2).
The overall number of suspicions of influenza and influenza-like infections in Poland was larger in the 2017/2018 season than that in 2016/2017: $5,337,619$ vs. $4,919,110$, respectively. Likewise, there were 18,320 hospitalizations and 48 deaths recorded due to influenza in the 2017/2018 season vs. 16,890 hospitalizations and 25 deaths in $2016 / 2017$.

In the 2016/2017 season, the incidence of influenza was 1,692 per 100,000 population. 
Table 2 Coinfections in the 2017/2018 epidemic season

\begin{tabular}{l|l|c}
\hline Patient age (years) & Type of coinfection & Epidemic week \\
\hline 16 & RSV + hCoV & 2 \\
\hline 7 & A/H3N2/ + B & 3 \\
\hline 9 & A/H3N2/ + B & 4 \\
\hline 70 & A/H3N2/ + B & 5 \\
\hline 5 & hCoV + PIV 1, 2, 3 & 5 \\
\hline 5 & PIV-1 + PIV 2 & 7 \\
\hline 64 & A/H1N1/pdm09+ B & 8 \\
\hline 33 & RSV + B & 8 \\
\hline 4 & A/H3N2/ + B & 9 \\
\hline 2 & RSV + B & 10 \\
\hline 3 & A/H1N1/pdm09+ B & 10 \\
\hline 71 & A + B & 10 \\
\hline 46 & A + B & 10 \\
\hline 3 & PIV-1 + hMPV & 10 \\
\hline 40 & A + B & 11 \\
\hline 35 & A/H3N2/ + B & 11 \\
\hline 69 & A + B & 12 \\
\hline
\end{tabular}

RSV, respiratory syncytial virus; hCoV, human coronavirus; $\mathrm{A}+\mathrm{B}$, influenza virus $\mathrm{A}$ and $\mathrm{B}$; PIV 1, 2, and 3, human parainfluenza virus type 1,2 , and 3 ; hMPV, human metapneumovirus

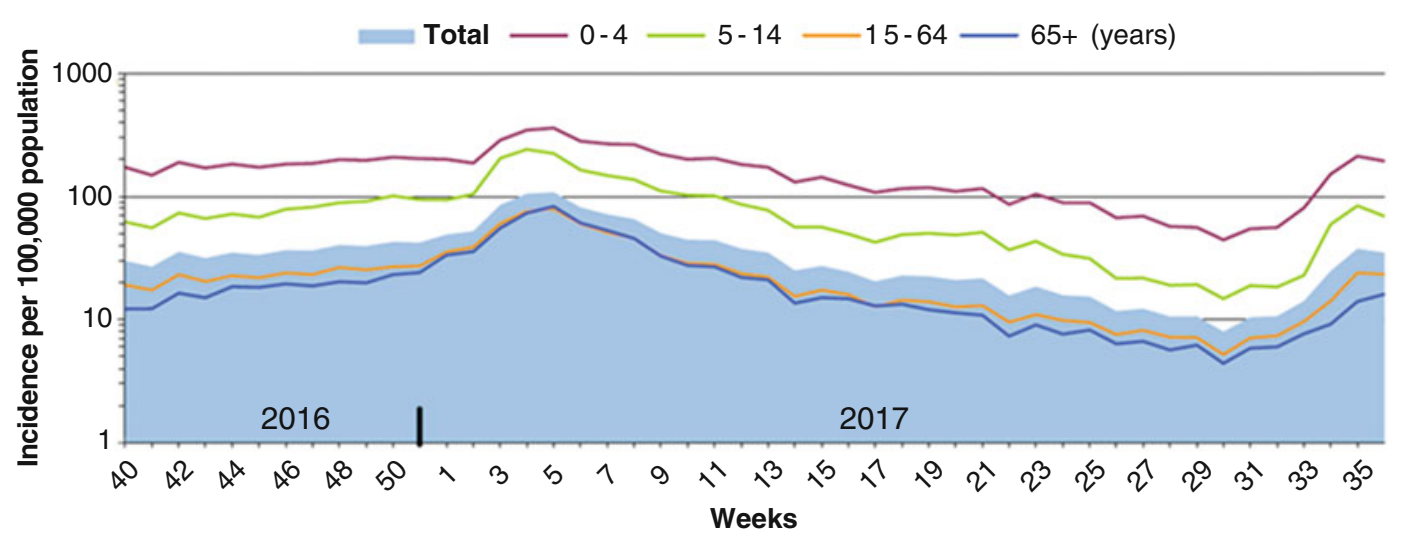

Fig. 3 Influenza and influenza-like infections in the 2016/2017 epidemic seasons in the Polish population by age groups, according to the National Institute of Public Health-National Institute of Hygiene in Warsaw

The influenza A virus, subtype A/H3N2/, was the predominant one in that season. However, in the most recent 2017/2018 epidemic season, the incidence was greater, exceeding 1,782 per 100,000 already by August of 2018. In this season, influenza B virus predominated, while $\mathrm{A} / \mathrm{H} 1 \mathrm{~N} 1 /$ pdm09 strain was most frequent among the influenza A subtypes. The peak incidence, based on the number of clinical specimens tested, was in weeks 4-5 of 2017 and week 8 of 2018 in the respective seasons (Figs. 3 and 4).

Across the whole of Europe, virus type A subtype A/H3N2/predominated in the 2016/2017 season (ECDC 2017), which was akin to the epidemiological situation at the time in Poland. However, in the following 2017/2018 season, the predominance switched to type B Yamagata lineage virus in Europe. Among somehow less 


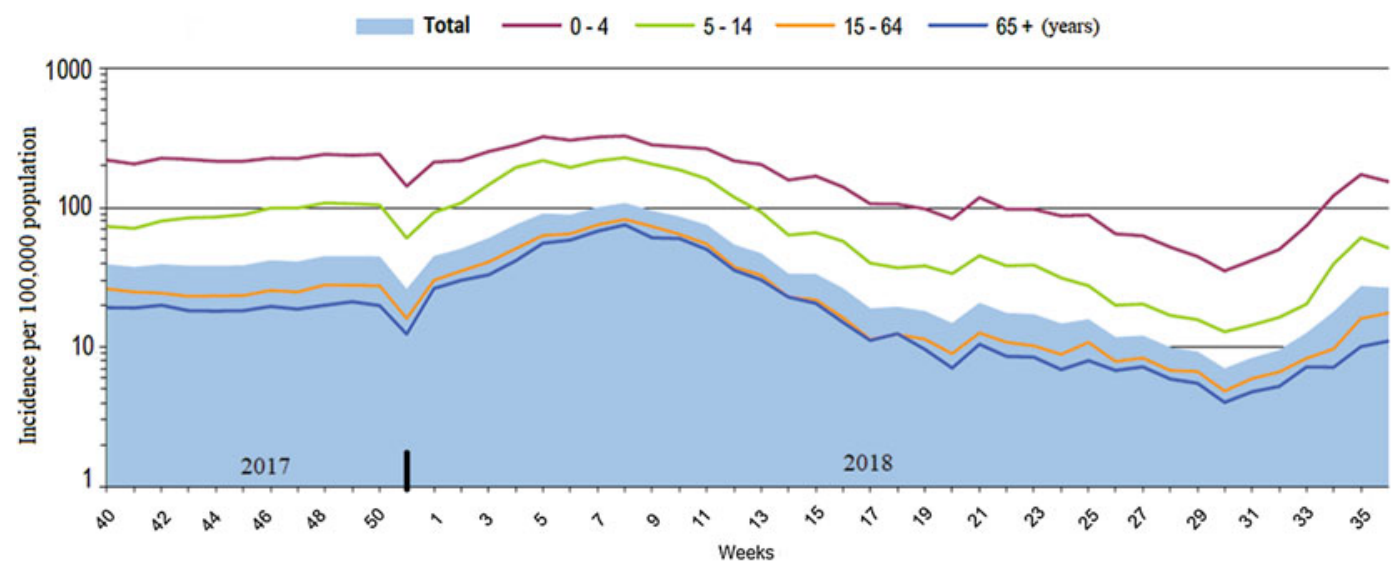

Fig. 4 Influenza and influenza-like infections in the 2017/2018 epidemic seasons in the Polish population by age groups, according to the National Institute of Public Health-National Institute of Hygiene in Warsaw

frequent influenza A infections, confirmed in 37\% of all cases, circulation of $\mathrm{A} / \mathrm{H} 1 \mathrm{~N} 1 / \mathrm{pdm} 09$ and A/H3N2/strains was most commonly noticed (Adlhoch et al. 2018; ECDC 2018). In this season, the epidemic was longer than usual (Groeneveld et al. 2018). Influenza A/H3N2/virus infections are considered more severe and more often affecting people over the age of 65 , leading to outbreaks in long-term nursing homes and causing a high rate of hospitalization and mortality in this age group. $B$ viruses, on the other side, are described as causing a milder disease and affecting younger age groups (Webster et al. 2013).

In conclusion, the recent 2017/2018 epidemic season clearly consisted of the increased number and severity of influenza infections, with a shift from type A to type B virus predominance. This report underscores a fleeting viral multifariousness of influenza infection and the need to prepare adequate anti-influenza shots every season. To this end, a quadrivalent vaccine, consisting of two antigens of influenza A subtypes and another two of type B virus, was introduced in Poland as of the 2017/2018 season. Nonetheless, the vaccination rate remained at a dismal level, one of the lowest in Europe, fluctuating between 3\% and $4 \%$ of the general Polish population. Thus, the epidemiological situation calls for the continuing promotion of awareness and education in the fight against influenza infection through the vaccination programs across all of the population segments.
Acknowledgments Funded by NIPH-NIH thematic subject 4/EM. We would like to acknowledge physicians and employees of the Voivodship Sanitary Epidemiological Stations across the country who collected epidemiological data for the Sentinel program in the framework of influenza surveillance in Poland.

Conflicts of Interest The authors declare no conflicts of interest in relation to this article.

Ethical Approval All procedures performed in studies involving human participants were in accordance with the ethical standards of the institutional and/or national research committee and with the 1964 Helsinki declaration and its later amendments or comparable ethical standards. The study was approved by an institutional Ethics Committee.

Informed Consent Informed consent was obtained from all individual participants included in the study before collection of nasopharyngeal samples.

\section{References}

Adlhoch C, Snacken R, Melidou A, Ionescu S, Penttinen $\mathrm{P}$, The European Influenza Surveillance Network (2018) Dominant influenza A(H3N2) and B/Yamagata virus circulation in EU/EEA, 2016/17 and 2017/18 seasons, respectively. Euro Surveill 23(13)

Bednarska K, Hallmann-Szelińks E, Kondratiuk K, Rabczenko D, Brydak LB (2016) Novelties in influenza surveillance in Poland. Probl Hig Epidemiol 97(2):101-105 
Brydak LB (2008) Influenza, pandemic flu, myth or real threat? Rythm, Warsaw, pp 1-492. (Book in Polish)

Caini S, Huang QS, Ciblak MA, Kusznierz G, Owen R, Wangchuk S, Henriques CM, Njouom R, Fasce RA, Yu H, Feng L, Zambon M, Clara AW, Kosasih H, Puzelli S, Kadjo HA, Emukule G, Heraud JM, Ang LW, Venter M, Mironenko A, Brammer L, Mai le TQ, Schellevis F, Plotkin S, Paget J, Global Influenza B Study (2015) Epidemiological and virological characteristics of influenza B: results of the global influenza B study. Influenza Other Respir Viruses 1 (9 Suppl):3-12

ECDC (2017) European center for disease prevention and control. Influenza in Europe, summary of the season 2016-2017. https://ecdc.europa.eu/en/seasonal-influ enza/season-2016-17. Accessed on 24 June 2019

ECDC (2018) European center for disease prevention and control. Influenza in Europe, summary of the season 2017-2018. https://ecdc.europa.eu/en/seasonal-influ enza/season-2017-18. Accessed on 24 June 2019

Groeneveld GH, Spaan WJ, van der Hoek W, van Dissel JT (2018) The severe flu season of 2017-2018: making a case for the vaccination of healthcare professionals. Ned Tijdschr Geneeskd 6:162
Socan M, Prosenc K, Ucakar V, Berginc N (2014) A comparison of the demographic and clinical characteristics of laboratory confirmed influenza B Yamagata and Victoria lineage infection. J Clin Virol 61(1):156-156

Tong S, Zhu X, Lil Y, Shi M, Zhang J, Bourgeois M, Yang H, Chen X, Recuenco S, Gomez J, Chen LM, Johnson A, Tao Y, Dreyfus C, Yu W, McBride R, Carney PJ, Gilbert AT, Chang J, Guo Z, Davis CT, Paulson JC, Stevens J, Rupprecht CE, Holmes EC, Wilson IA, Donis RO (2013) New world bats harbor diverse influenza a viruses. PLoS Pathog 9(10): e1003657

Vijaykrishna D, Holmes EC, Joseph U, Fourment M, Su YC, Halpin R, Lee RT, Deng YM, Gunalan V, Lin X, Stockwell TB, Fedorova NB, Zhou B, Spirason N, Kühnert D, Bošková V, Stadler T, Costa AM, Dwyer DE, Huang QS, Jennings LC, Rawlinson W, Sullivan SG, Hurt AC, Maurer-Stroh S, Wentworth DE, Smith GJ, Barr IG (2015) The contrasting phylodynamics of human influenza B viruses. elife 4:e05055

Webster RG, Monto AS, Braciale TJ, Lamb RA (2013) Textbook of influenza, 2nd edn. Wiley, Hoboken, pp 392-418 